\title{
ESTUDO DA CONTAMINAÇÃO DA SUBSUPERFÍCIE POR HIDROCARBONETOS EM POSTOS DE COMBUSTÍVEIS NA CIDADE DE BRAGANÇA (BRASIL) APLICANDO $O$ GPR
}

\author{
Pamela Oliveira da Costa ${ }^{1}$, Rubenilson Procópio Brito ${ }^{1}$, Pedro Chira-Oliva ${ }^{1 *}$ \\ ${ }^{1}$ Instituto de Estudos Costeiros (IECOS), Universidade Federal do Pará, Brasil, *e-mail: chira@ufpa.br
}

Copyright 2014, SBGf - Sociedade Brasileira de Geofísica

Este texto foi preparado para a apresentação no VI Simpósio Brasileiro de Geofísica Porto Alegre, 14 a 16 de outubro de 2014. Seu conteúdo foi revisado pelo Comitê Técnico do VI SimBGf, mas não necessariamente representa a opinião da SBGf ou de seus associados. É proibida a reprodução total ou parcial deste material para propósitos comerciais sem prévia autorização da SBGf.

\begin{abstract}
In the state of Pará (Brazil), there exist 948 registered gas and oil stations. These establishments turned out to be the principal causes of contamination of the environment mainly by fuel (gasoline, alcohol, and diesel), due to the corrosion and cracks in tanks and tubing. In Bragança city (Pará, Brazil) is common to find gas and oil stations and little is known about the possible risks that these stations can cause to the soil and groundwater of this city. For the majority, these stations were constructed in the 1970s and 1980s, which causes serious problems due to the fact that these subterranean storage tanks have a median life of up to 25 years. In this paper applied the Ground Penetrating Radar (GPR) to characterize the spatial distribution of possible plumes of hydrocarbons, in function of geological, hydrogeological and geophysical aspects of the Gas and Oil stations located in Bragança city, Pará. This application is of great relevance to alert local authorities on environmental impact that produces subsurface contamination due to leaks originating from gas and oil stations. Furthermore, this study can contribute initiating the process of monitoring these stations to reduce and even eliminate contaminated subsurface of the same areas.
\end{abstract}

\section{Introdução}

A contaminação do solo e das águas subterrâneas é um fator preocupante que pode acarretar diversos prejuízos à saúde humana e causar danos irrecuperáveis ao meio ambiente.

Segundo a Agência Nacional do Petróleo (ANP), no Pará existem 948 postos de combustíveis cadastrados (ANP, 2012). Esses estabelecimentos tornaram-se os principais causadores de contaminação do meio ambiente que ocorre principalmente através do vazamento de combustíveis (gasolina, álcool e diesel), devido à corrosão e rachaduras de tanques e tubulações.

Nos tanques subterrâneos de armazenamento de combustíveis dos postos de abastecimento, a detecção de vazamentos torna-se muito difícil de ser verificada previamente, principalmente pela dificuldade de observação direta. Extensas zonas contaminadas podem se formar no subsolo sem possibilitar a identificação de vestígios contundentes em superfície (ALMEIDA, 2007).
As técnicas geofísicas, dentre outros fatores, possibilitam a detecção da contaminação de maneira rápida e eficiente, como também através das propriedades físicas e químicas dos materiais da subsuperfície (SOUZA, 2005).

Os principais e mais adequados métodos geofísicos que comumente são aplicados à investigação da contaminação do solo e da água subterrânea são: o Ground Penetrating Radar (GPR), o eletromagnético indutivo (EM), a eletrorresistividade (ER) e a magnetometria. Dentre estes, o geo-radar é o método indireto que vem sendo mais eficientemente utilizado na detecção de plumas de contaminação de hidrocarbonetos provocadas por vazamentos de combustíveis (CETESB, 1999). Desse modo, a investigação indireta da subsuperfície tornou-se bastante favorável na detecção de plumas de contaminação por hidrocarbonetos (Pedrosa et al., 2006; Almeida, 2007; Sousa, 2009), localização de tanques, tubulações, etc, entre outras aplicações.

Em Bragança (nordeste do estado do Pará) existem postos de combustíveis e há a preocupação em relação aos possíveis danos que estes estabelecimentos podem ocasionar ao solo e às águas subterrâneas do município. Em sua grande maioria, esses postos foram construídos nas décadas de 70 e 80 , o que gera um fator-problema, pois tanques de armazenamento subterrâneos possuem uma vida útil média de 25 anos (CORSEUIL \& MARINS, 1997). Assim, supõe-se que tais postos já estejam comprometidos, apresentando problemas e oferecendo vários tipos de perigos aos moradores adjacentes, dentre os quais, destacam-se riscos de explosões e incêndios e contaminação dos lençóis freáticos.

Diante do problema exposto, o presente trabalho visa verificar e caracterizar a distribuição espacial de possíveis plumas de contaminação de hidrocarbonetos que possam existir na subsuperfície dos principais postos de revenda de combustíveis automotivos em Bragança (estado do Pará), com base nos dados geofísicos GPR. Esta aplicação é de grande relevância, pois o estudo é pioneiro no município e pretende alertar as autoridades locais para o grave impacto ambiental provocado pela contaminação do subsolo proveniente de vazamentos originados de postos de combustíveis. Além disso, esse estudo pode ajudar a dar início ao processo de monitoramento destes postos para reduzir e até eliminar as áreas contaminadas na subsuperfície dos mesmos. 


\section{Materiais e métodos}

\section{Área de estudo}

A área de estudo está localizada no município de Bragança, nordeste do estado do Pará, onde estão localizados os postos de abastecimento de combustíveis estudados (Figura 1). O município de Bragança está localizado geograficamente a uma latitude $1^{\circ} 03^{\prime} 57.43^{\prime \prime}$ Sul e longitude $46^{\circ} 47^{\prime} 22.24^{\prime \prime}$ Oeste (Figura 1).

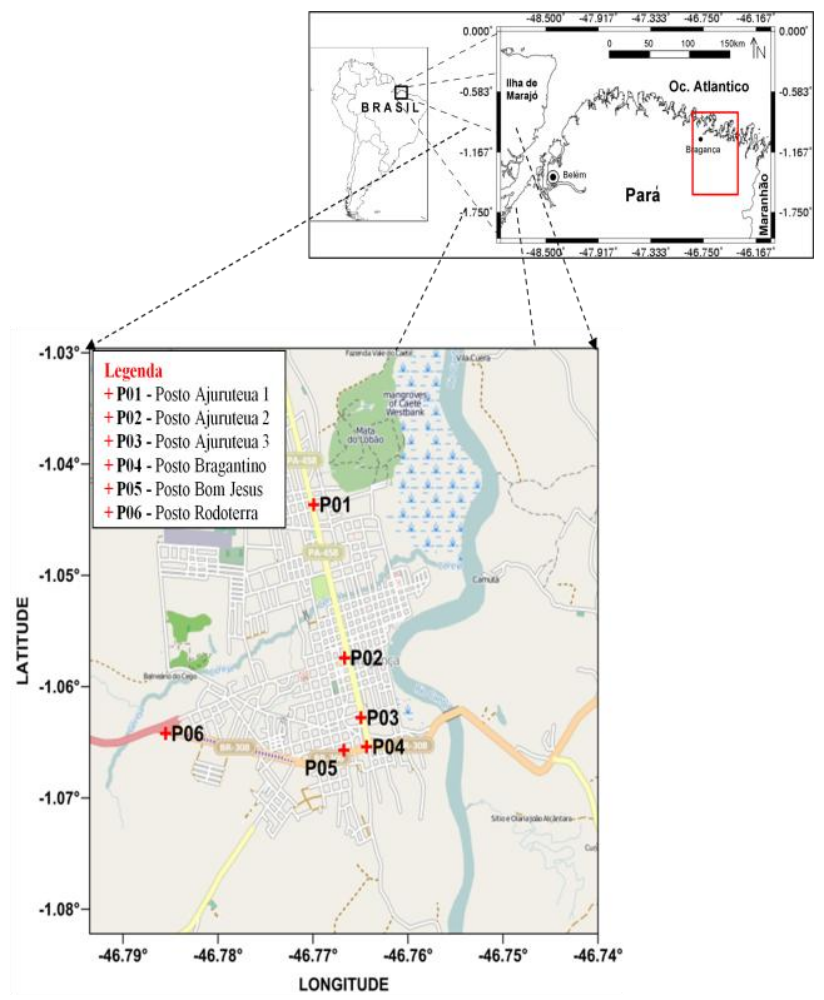

Figura 1 - Localização da área de estudo com destaque para os postos de abastecimento de combustíveis estudados, no município de Bragança (Pará, Brasil).

\section{O Método Ground Penetrating Radar (GPR)}

O radar de penetração no solo ou GPR é um método geofísico indireto que consiste na emissão de ondas eletromagnéticas de alta frequência. $O$ princípio do funcionamento do GPR baseia-se na emissão, reflexão e recepção da onda, que responde às propriedades dielétricas do solo, no qual o sinal - a onda eletromagnética - se propagará (Furtado, 2009). A onda de energia eletromagnética é irradiada para a subsuperfície por uma antena transmissora, sendo a energia transmitida para profundidades maiores e parte dela refletida para a superfície, quando esta encontrar no interior do solo materiais geológicos com propriedades eletromagnéticas diferentes. $O$ pulso eletromagnético refletido é captado pela antena receptora, sendo o sinal, então, registrado, amplificado, gravado e apresentado na tela de um computador através de uma assinatura eletromagnética denominado de "radargrama", para processamento e análise posterior.

\section{Aquisição de dados}

As coletas dos dados geofísicos (dados GPR) foram realizadas com um equipamento da empresa GSSI SIR3000 sendo a antena utilizada de $400 \mathrm{MHz}$ de frequência e a janela temporal de 50 ns (nanosegundos).

A configuração fonte-receptor considerada neste levantamento de dados foi do tipo afastamento comum ou Common-Offset com arranjo monoestático, ou seja, apenas uma antena emite e recebe 0 sinal eletromagnético. Este arranjo foi escolhido em função da disponibilidade de instrumento com esta configuração. Os espaços compreendidos para a obtenção do sinal foram de 5 metros para os perfis internos e 10 metros para os perfis externos às áreas dos postos de abastecimentos de combustíveis. As coletas ocorreram no período não chuvoso de 2011 (mês de novembro) e chuvoso de 2012 (mês de março).

Para esta coleta foram considerados seis postos de abastecimento deste município, sendo eles: Posto Ajuruteua 1 - (P01); Posto Ajuruteua 2 - (P02); Posto do Ajuruteua 3 - (P03); Posto Bragantino - (P04); Posto Bom Jesus - (P05) e Posto Rodoterra - (P06) (Figura 1). A escolha dependeu da facilidade e disponibilidade dos mesmos para estas coletas..

\section{Resultados}

A seguir serão apresentados os principais resultados gerados a partir da aplicação da ferramenta geofísica GPR no estudo realizado nos postos de combustíveis localizados na cidade de Bragança (Pará, Brasil).

\section{Posto Ajuruteua 1}

No posto "Ajuruteua 1" (P01) foram levantadas seis linhas de perfis GPR com comprimento variando entre 35 a 150 metros, respectivamente.

\section{Período não chuvoso 2011}

Podemos observar no perfil L3 (Figura 2) o registro de hipérboles demostrando a existência de tubulações ou de tanques de armazenamento desativados.

Observa-se no perfil L4 (Figura 3) uma zona de baixa reflexão compreendida entre as posições de 60 a 150 metros e até uma profundidade aproximada de 3,2 metros.

Neste mesmo perfil é possível observar ainda a presença de uma faixa vertical contínua na posição de 14,5 metros e na profundidade que vai além da base do radargrama (profundidade de penetração do sinal), indicando possivelmente a presença de um poço artesiano.

Também foi detectado no perfil L4 (Figura 3) a presença de um refletor contínuo e forte, localizado a uma profundidade aproximada de 3 metros, o que nos estaria indicando a localização do nível do lençol freático. 


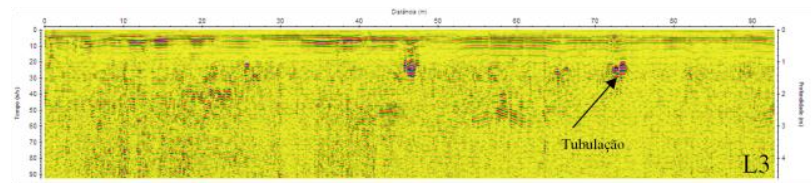

Figura 2 - Radargrama do perfil L3 (Posto Ajuruteua 1, novembro de 2011).

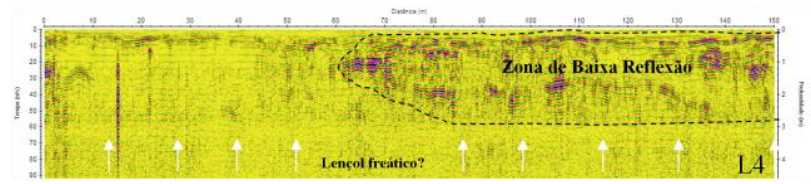

Figura 3 - Radargrama do perfil L4 (Posto Ajuruteua 1, novembro de 2011).

Período chuvoso 2012

Para o período chuvoso de 2012 (mês de março) foram consideradas as mesmas linhas de perfis do período anterior.

Denota-se a presença de eventos de reflexão na forma de hipérboles, o que poderiam estar indicando a presença de tubulações enterradas na subsuperfície (Figura 4).

No perfil L6 (Figura 5) observa-se uma zona de baixa reflexão que chega até uma profundidade aproximada de 2,5 metros e que estaria nos indicando a presença de contaminação da subsuperfície por hidrocarbonetos.

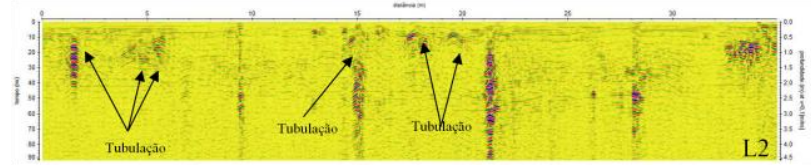

Figura 4 - Radargrama do perfil L2 (Posto Ajuruteua 1, março de 2012).

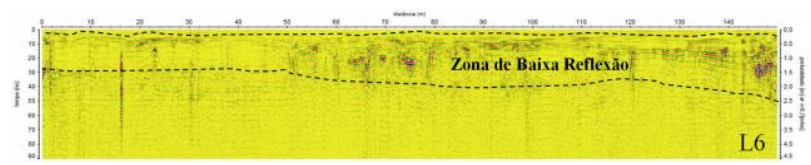

Figura 5 - Radargrama do perfil L6 (Posto Ajuruteua 1, março de 2012).

\section{Posto "Ajuruteua 2"}

No posto "Ajuruteua 2" $\mathrm{P}(02)$ foram levantados sete linhas de perfis GPR com comprimentos variando entre 26 a 80 metros, respectivamente.

\section{Período não chuvoso 2011}

No período não chuvoso foram levantados apenas seis linhas de perfis GPR por impossibilidade do equipamento GPR percorrer o perfil L6, pois havia um parque no local.

Os principais perfis referentes ao período não chuvoso de 2011 (mês de novembro) são apresentados nas Figuras 6 e 7.
O perfil L1 (Figura 6) mostra evidentemente a localização dos tanques de armazenamento de combustíveis nos registros dos eventos de reflexão na forma de hipérboles.

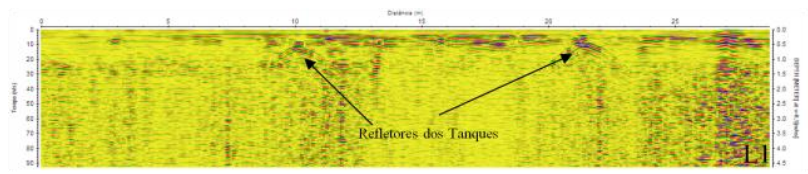

Figura 6 - Radargrama do perfil L1 (Posto Ajuruteua 2, novembro de 2011).

Observa-se no perfil L5 (Figura 7) uma zona de baixa reflexão compreendida entre as posições de 22 a 55 metros e até uma profundidade aproximada de 2,6 metros. Esta zona, como no posto anterior, estaria nos indicando a presença da contaminação da subsuperfície por hidrocarbonetos proveniente dos tanques de armazenamento deste posto.

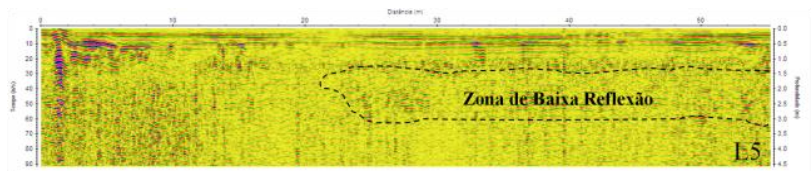

Figura 7- Radargrama do perfil L5 (Posto Ajuruteua 2, novembro de 2011)

Período chuvoso 2012

No período chuvoso de 2012 (mês de março) foram levantadas sete linhas de perfis GPR.

Foram detectados eventos de reflexão na forma de hipérboles (perfil L1, Figura 8) que estariam nos indicando a presença dos tanques de armazenamento de combustíveis neste posto.

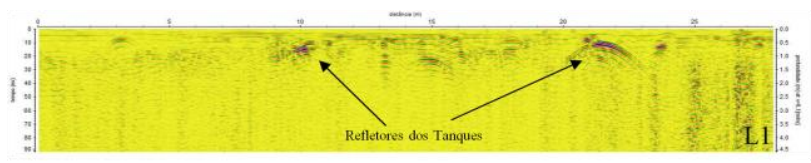

Figura 8 - Radargrama do perfil L1 (Posto Ajuruteua 2, março de 2012).

No perfil L5 (Figura 9) observa-se uma zona de baixa reflexão fraca (menos intensa que no período não chuvoso), possível zona de contaminação existente na subsuperfície deste posto, nos espaços de 20 a 55 metros e profundidade de 2,5 metros.

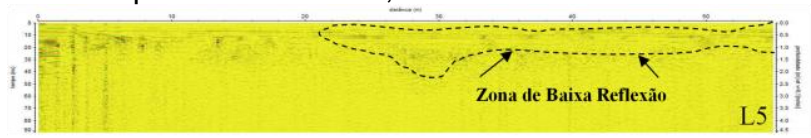

Figura 9 - Radargrama do perfil L5 (Posto Ajuruteua 2, março de 2012).

\section{Posto "Ajuruteua 3"}

No posto "Ajuruteua 3" $\mathrm{P}(03)$ foram levantadas seis linhas de perfis GPR com comprimento variando entre 35 a 70 $\mathrm{m}$. 
Período não chuvoso 2011

Neste período foram levantados 06 perfis. No perfil L1 representado pela Figura 10 observa-se uma zona de baixa reflexão que se estende por todo o radargrama, sendo mais intensa em sua parte central e que pode indicar uma possível contaminação por hidrocarbonetos. Esta zona detectada atinge uma profundidade aproximada de 3,0 metros.

No caso do perfil L2 representado pela Figura 11, observa-se a presença de formas hipérbólicas no sinal do evento de reflexão que indica a presença de tubulações e a localização dos tanques de armazenamento de combustível.

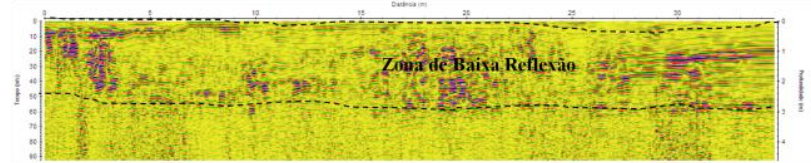

Figura 10 - Radargrama do perfil L1 (Posto Ajuruteua 3, novembro de 2011).

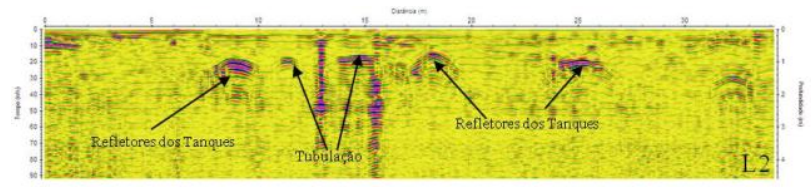

Figura 11 - Radargrama do perfil L2 (Posto Ajuruteua 3, novembro de 2011).

Período chuvoso 2012

Foram seis perfis os levantados durante este período para este posto de abastecimento de combustíveis.

No perfil L2 (Figura 12) destaca a presença de sinais eletromagnéticos com boas amplitudes (hipérboles), como acontece no caso do período não chuvoso (novembro de 2011) que está indicando a presença na subsuperfície dos tanques de armazenamento de combustível do referido posto.

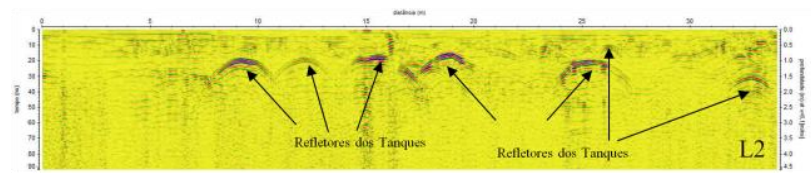

Figura 12 - Radargrama do perfil L2 (Posto Ajuruteua 3, março de 2012)

No perfil L5 do período chuvoso, representado pela Figura 13, também observa-se uma zona de baixa reflexão pouco intensa que se estende em uma faixa contínua por todo o radargrama, atingindo uma profundidade aproximada de 2,5 metros.

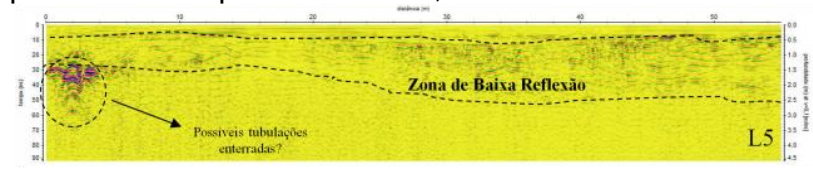

Figura 13 - Radargrama do perfil L5 (Posto Ajuruteua 3, março de 2012)

\section{Posto "Bragantino"}

No posto "Bragantino" $\mathrm{P}(04)$ foram levantadas quatro linhas de perfis GPR com comprimento variando entre 30 a 50 metros.

Período não chuvoso 2011

No período não chuvoso de 2011 (mês de novembro), foram detectadas tubulações no perfil $L 1$, representado principalmente pela Figura 14.

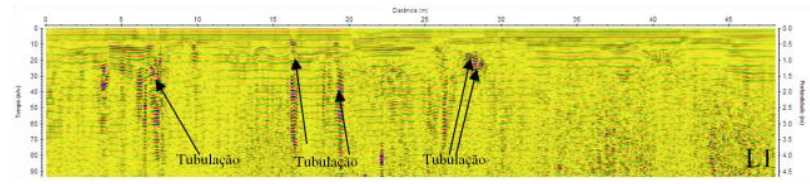

Figura 14 - Radargrama do perfil L1 (Posto Bragantino, novembro de 2011).

Período chuvoso 2012

Foram levantados quatro perfis referentes a este período chuvoso de 2012 (mês de março).

Foram detectados em profundidade os tanques de armazenamento de combustíveis (ondas de grandes amplitudes) principalmente no perfil $\mathrm{L} 2$, representado pela Figura 15.

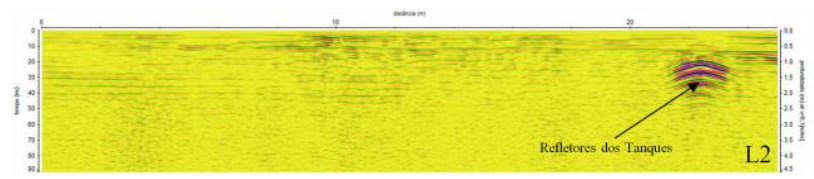

Figura 15 - Radargrama do perfil L2 (Posto Bragantino, março de 2012).

As possíveis zonas de contaminação por hidrocarbonetos não foram registradas nos radargramas deste posto.

\section{Posto "Bom Jesus"}

Neste posto somente foram levantados dois perfis GPR (Figura 14) devido a dificuldade de acesso para este local. Estas coletas aconteceram no período não chuvoso de 2011 (mês de novembro) e chuvoso de 2012 (mês de março).

O principal perfil L3 referente ao período não chuvoso de 2011 é apresentado na Figura 16. Nela observa-se uma zona de baixa reflexão, aproximadamente entre os espaços de 18 a 50 metros e uma profundidade aproximada de 3,0 metros, que poderia estar indicando uma alta argilosidade do subsolo.

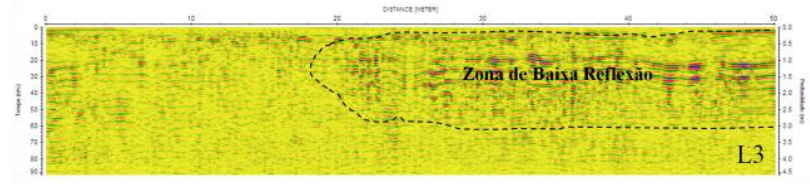

Figura 16 - Radargrama do perfil L3 (Posto Bom Jesus, novembro de 2011)

O mesmo perfil L3 (Figura 17) referente ao período chuvoso de 2012 apresenta uma zona de baixa reflexão 
menos intensa que a do período não chuvoso, localizada entre os espaços de 8 a 50 metros e uma profundidade aproximada de 3 metros.

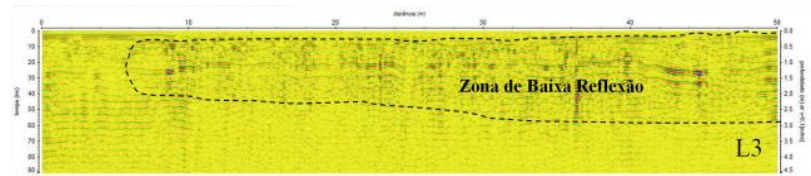

Figura 17 - Radargrama do perfil L3 (Posto Bom Jesus, março de 2012).

\section{Posto "Rodoterra"}

No posto "Rodoterra" $P(06)$ foram levantadas quatro linhas de perfis GPR com comprimento variando entre 73 a $80 \mathrm{~m}$.

\section{Período não chuvoso 2011}

Os perfis mais representativos levantados no período não chuvoso (novembro, 2011) são dados pelos perfis L1 e L2, respectivamente.

No perfil L1 do período não chuvoso (mês de novembro), representado pela Figura 18, observa-se uma zona de baixa reflexão intensa, extensa e contínua ao longo de todo o comprimento do perfil analisado, a uma profundidade máximaa de 3,5 metros. Também pode-se observar nesse perfil a presença de uma linha ou reflector contínuo e ligeiramente forte a uma profundidade aproximada de 3 metros, indicando possivelmente a presença do nível do lençol freático.

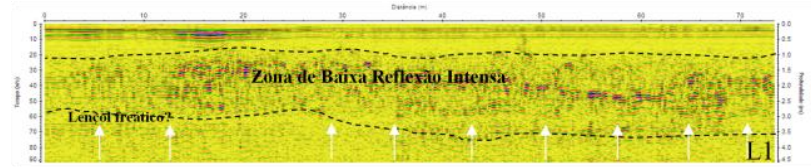

Figura 18 - Radargrama do perfil L1 (Posto Rodoterra, novembro de 2011).

No caso do perfil L2 representado pela Figura 19, o método GPR permitiu identificar eventos de reflexão na forma de hipérboles que estariam evidenciando a presença dos tanques de armazenamento de combustíveis.

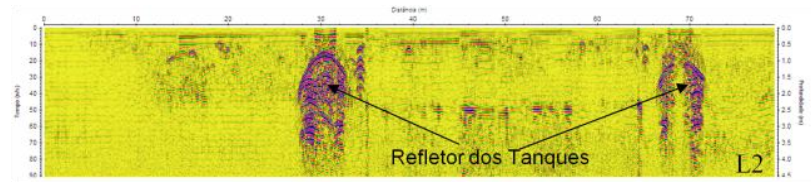

Figura 19 - Radargrama do perfil L2 (Posto Rodoterra, novembro de 2011).

\section{Período chuvoso 2012}

Da mesma forma, como no período não chuvoso, observa-se que no perfil L1 do período chuvoso (Figura 20), apresenta-se uma zona de baixa reflexão (pouco intensa) extensa e contínua ao longo de todo o perfil analisado, a uma profundidade aproximada de 3,1 metros.

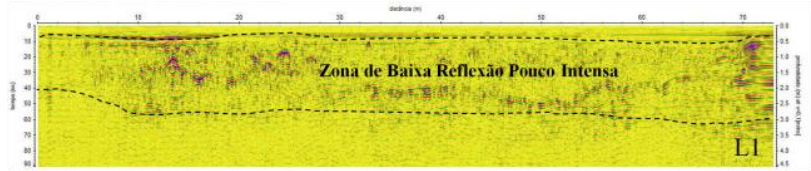

Figura 20 - Radargrama do perfil L1 (Posto Rodoterra, março de 2012).

Da mesma maneira, observam-se eventos de reflexão na forma de hipérboles no perfil L2, representado pela Figura 21, porém com menor intensidade que no anterior período.

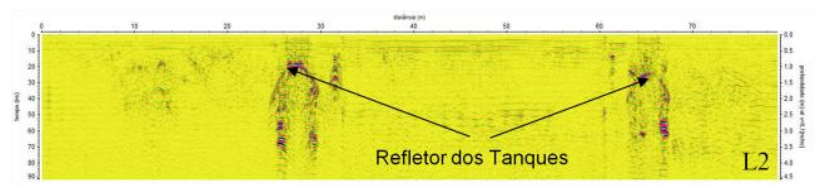

Figura 21 - Radargrama do perfil L2 (Posto Rodoterra, março de 2012).

\section{Conclusões}

$O$ radar de penetração no solo (GPR) utilizado neste estudo permitiu caracterizar o problema da possível contaminação por hidrocarbonetos da subsuperfície dos postos de abastecimento na cidade de Bragança (Pará, Brasil).

Verificou-se que cinco postos apresentam registros de zonas de baixa reflexão do smal eletromagnético, que representam a possível contaminação ambiental por hidrocarbonetos na subsuperfície, proveniente dos tanques de armazenamento destes postos. Estes postos são: Ajuruteua 1 (P01), Ajuruteua 2 (P02), Ajuruteua 3 (P03), Posto Bom Jesus (P05) e Posto Rodoterra (P06). $\mathrm{O}$ único posto de abastecimento que não apresentou zonas de atenuação do sinal foi o Posto Bragantino (P04).

Deve-se atentar para o caso dos postos que apresentaram zonas de baixa reflexão intensa (Posto 01, 03 e 06). Estes postos são considerados como possivelmente contaminados por serem evidentes e intensas as zonas de atenuação de sinal e pela característica caótica desses eventos de reflexão. O mesmo também acontece com o posto Ajuruteua 2 (P02), porém apresenta uma zona de baixa reflexão muito fraca. Foi verificado que as possíveis zonas de contaminação detectadas, atingem o lençol freático nos postos P01 e P06. O lençol freático está localizado a uma profundidade aproximada de 3 metros; apresentando-se como um refletor contínuo e ligeiramente forte.

\section{Agradecimentos}

Ao Programa Institucional de Bolsas de Iniciação Cientifica (PIBIC/UFPA) pela disponibilidade de bolsa de Iniciação Científica para o segundo autor.

\section{Referências}

AGÊNCIA NACIONAL DE PETRÓLEO, GÁS NATURAL E BIOCOMBUSTÍVEIS (ANP), 2012. Disponível em: 
<http://www.anp.gov.br/?pg=62463\&m=anu\%E1rio\%20es tat\%EDstico\%202012\&t1=\&t2=anu\%E1rio\%20estat\%EDs tico\%202012\&t3=\&t4=\&ar=0\&ps=1\&cachebust $=1384290$ $612058>$.

ALMEIDA, F. M., 2007. Estudo da contaminação por hidrocarbonetos em postos de serviços do município de Abaetetuba- PA utilizando georadar. Dissertação de Mestrado, Universidade Federal do Pará, 142pp.

CORSEUIL, H. X.. MARINS, M. D. M., 1997. Contaminação de Águas Subterrâneas por Derramamentos de Gasolina: O Problema É Grave? Revista Engenharia Sanitária e Ambiental 2: 50-54.

FURTADO, P. Q. F., 2009. Processamento e modelagem de dados de GPR utilizando o REFLEXW 4.5. Trabalho de Conclusão de Curso, Universidade Federal do Pará, $41 \mathrm{pp}$.

PEDRosA, T. R. M. A. M., CASTRO, D. L. C., CASTELO B., R. M. G., 2006. Caracterização de plumas contaminantes de hidrocarbonetos em postos de abastecimento em Fortaleza, usando o método Radar de Penetração do Solo (GPR). Revista de Geologia 19: 7386.

SOUZA A. C. P., 2009. Uso do GPR na caracterização da pluma de contaminação gerada por hidrocarbonetos a partir de um posto de combustível na praia de Búzios/RN. Dissertação de Mestrado, Universidade Federal do Rio Grande do Norte, 69pp.

SOUZA, M. M., 2005. Uso de georadar pra investigações ambientais. Dissertação de Mestrado, Pontifícia Universidade Católica do Rio de Janeiro, 120 p. 